\title{
UMA EXPERIÊNCIA DE EDUCAÇÃO HÍBRIDA: ESTUDO DE CASO EM UM CURSO DE PÓS-GRADUAÇÃO
}

\author{
Rafael Fonseca de Castro - rafaelfdecastro@ gmail.com - UFPel \\ Magda Floriana Damiani - flodamiani@gmail.com - UFPel
}

\section{Resumo}

A presente pesquisa objetivou investigar, a partir das impressões dos sujeitos, aspectos relacionados a uma experiência educacional híbrida de uma turma de um curso de pósgraduação que, em duas disciplinas da sua grade curricular, utilizou o AVEA TelEduc concomitantemente às aulas presenciais físicas tradicionais. Tratou-se de um estudo de caso, baseado em uma análise de dados coletados por meio de questionários e análise de documentos - postagens em fóruns. Os achados da pesquisa sugerem que: os sujeitos consideram fundamental a utilização pedagógica das novas tecnologias; alertam sobre a forma como estas devem ser empregadas; e avaliaram como bastante positiva a experiência educacional hibrida que vivenciaram. Com efeito, esta investigação também visa colaborar com o debate 'educação-tecnologia'.

Palavras-chave: educação híbrida, AVEA, ensino, aprendizagem, tecnologia.

\section{A HYBRID EDUCATION EXPERIENCE: CASE STUDY OF A POSTGRADUATE COURSE}

\begin{abstract}
This study was aimed at investigating, from the their own perspective, issues related to a hybrid educational experience of a group of postgraduate students in two disciplines of its curriculum, using AVEA TelEduc learning space concomitantly with traditional lessons in a physical presence context. The case study was based on an analysis of data collected through questionnaires and documental analysis - of forum posts. The findings suggest that: the students consider the pedagogical use of the new technologies to be fundamental; they suggest ways in which these technologies should be used; and they rated positively their hybrid educational experiences. In addition to such findings, this investigation aimed at collaborating with the 'education-technology' relation debate.
\end{abstract}

Key-words: hybrid education, e-learning space, teaching, learning, technology.

\section{Introdução}

O aproveitamento pedagógico das tecnologias - Tecnologias da Informação e da Comunicação (TIC) e Tecnologias Digitais Virtuais (TDV) - na educação vem se constituindo, ao longo dos anos, em um tema polêmico e cada vez mais importante, dentro e fora da academia. $\mathrm{Na}$ educação, de forma sistemática, opiniões divergem e avanços importantes começam a ser percebidos acerca da utilização pedagógica das novas tecnologias, principalmente em projetos de Educação a Distância (EaD).

Respeitando crenças e opiniões, sejam essas de ordem prática ou teórica, este estudo parte da hipótese de que a educação não pode andar na contramão de uma realidade histórico-cultural pertinente à educação atual: o uso de recursos tecnológicos de interação e comunicação. $\mathrm{O}$ artigo defende também que a educação do século XXI, a exemplo de outros setores da sociedade, deve usufruir do leque de possibilidades aberto pelas tecnologias - especialmente pelas áreas da Informática (hardware e software) e das Telecomunicações (redes de comunicação). 
Partindo desta perspectiva, o presente texto tem como objetivo relatar os achados de uma investigação que, a partir das impressões dos estudantes, investigou aspectos relacionados a uma experiência educacional híbrida (semipresencial ou bimodal) - que combinou encontros presenciais físicos ${ }^{1}$ tradicionais (sala de aula) e atividades pedagógicas em um Ambiente Virtual de Ensino e Aprendizagem (AVEA). Trata-se de uma pesquisa qualitativa, baseada em um Estudo de Caso em uma turma de um curso de Pós-Graduação Latto Sensu de uma instituição federal do sul do Brasil que, em duas disciplinas da sua grade curricular, conciliou pedagogicamente ambas as modalidades, constituindo, assim, uma experiência de educação hîbrida. Os dados desta pesquisa emergiram de relatos dos estudantes do referido curso, por meio de questionários e de análise documental de postagens em fóruns. Antes de apresentar a pesquisa propriamente dita, considera-se necessário discutir algumas ideias sobre Ambientes Virtuais de Ensino e Aprendizagem e Educação Hỉbrida.

\section{Ambientes Virtuais de Ensino e Aprendizage m e Educação Híbrida}

Um novo tempo, um novo espaço e outras maneiras de pensar e fazer educação são exigidos na sociedade da informação (LÉVY, 1999), por uma sociedade do conhecimento (FREIRE, 1997). O acesso e o uso das novas tecnologias acenam para a reorganização dos currículos, dos modos de pensar, da gestão e das metodologias utilizadas na prática educacional. Para Kenski (2003), tais alterações resultam em mudanças sensíveis no contexto educacional, tornando-se necessário considerar que o acesso e a utilização das novas tecnologias condicionam o uso de metodologias emergentes, de práticas educativas inovadoras. Lévy (2004) vai além e "profetiza" que as estruturas centralizadas perderão seu sentido e darão lugar a atitudes mais abertas e colaborativas que, inevitavelmente, tornar-se-ão novas referências no campo educacional.

Os AVEA são disponibilizados em sites educacionais, na internet. Schlemmer (2004) explica que são redes eletrônicas de comunicação interativa e autodefinida, organizadas em torno de um interesse ou finalidade compartilhados. Esse novo sistema de comunicação pode integrar todas as formas de expressão, bem como a diversidade de interesses, valores e imaginações, incluindo a expressão de conflitos. "Isso tudo devido à sua diversificação, multimodalidade e versatilidade" (idem, p. 2).

Segundo Schlemmer (2004), ambientes computacionais baseados na web podem propiciar que a inteligência do homem seja distribuída e se amplie em uma coletividade por meio da constituição de redes de convivência. Para esta autora, eles constituem, assim, um novo espaço relacional, com nova temporalidade, flexível. Valoriza-se cada vez mais a forma coletiva e interativa de aprendizagem. Para D'Ávila (2003, p. 284), nesta perspectiva, "são os educandos, num ambiente compartilhado, os mestres de si mesmos". Partindo desta premissa, um AVEA apresenta potencial para ser mais do que um simples espaço de publicação de materiais, de interações pré-definidas, pois se constitui em um ambiente onde os educadores podem estimular atividades de interação, de comunicação e de discussões colaborativas que cada contexto educacional específico demanda, mediante o uso de ferramentas atrativas ao processo educativo.

Inúmeras ferramentas computacionais voltadas à educação, nos moldes de um AVEA, foram propostas e desenvolvidas em todo o mundo. Rocha (2002) acrescenta que algumas obtiveram mais sucesso e passaram a ser exploradas comercialmente, enquanto outras permaneceram em uso restrito nas instituições que as desenvolveram. Tornaram-se mais populares os ambientes Moodle, WebCT, AulaNet, Lotus Learning Space e Second Life. No Brasil, o AVEA que atingiu maior visibilidade e utilização por parte do meio acadêmico, inicialmente, foi o Ambiente TelEduc - atualmente, o Moodle 
é o ambiente mais utilizado em projetos híbridos ou de EaD. Rocha (2002) explica que o TelEduc teve como meta inicial a formação de professores para a Informática na Educação. Seu desenvolvimento teve início em 1997, como resultado de uma proposta de dissertação de mestrado - o ambiente cresceu e se solidificou e sua primeira versão como Software Livre foi disponibilizada em 2001, passando a ser utilizada no Brasil por diversas instituições públicas de ensino.

Configura-se um cenário de consistente expansão de projetos em $\mathrm{EaD}$, sendo estes, em muitos casos, invariavelmente comparados à educação presencial física tradicional. Contudo, em meio a esse dualismo que se estabelece, dentro e fora do meio acadêmico, ainda se discute pouco sobre projetos que inter-relacionem atividades pedagógicas presenciais físicas e virtuais. Sobre a concomitância da educação presencial física tradicional e a educação a distância - educação híbrida -, Brod e Rodrigues (2009) explicam que

\begin{abstract}
cursos híbridos combinam o melhor dos dois mundos, potencializam as relações de ensino e aprendizagem e estabelecem um canal de interatividade espontânea. Por meio das interações recorrentes, surge um novo paradigma, o da aprendizagem cooperativa e colaborativa, onde o profes sor possui nova postura: de transmissor de conhecimento para mediador entre o educando e o conhecimento (p. 2).
\end{abstract}

Segundo Palloff e Pratt (1999, p. 130), "um curso ministrado tanto presencialmente quanto on-line pode dar aos educandos a oportunidade de alternarem o modo como aprendem, dependendo da necessidade e da capacidade de trabalhar neste ou naquele sistema". Na medida em que um ambiente pedagógico tenha como meta criar situações de aprendizagem significativas e mediante um projeto de ensino com disponibilidade subjetiva e objetiva para estabelecer diálogo permanente, tal ambiente pode até ultrapassar as condições atuais do regime presencial físico tradicional.

Santana et. al. (2006) buscaram avaliar uma experiência educacional híbrida em uma disciplina de um curso de graduação. A partir dessa investigação, evidenciaram críticas positivas dos alunos em relação à utilização do AVEA Moodle e suas ferramentas, sublinhando o melhor desenvolvimento desta disciplina do que em disciplinas presenciais físicas tradicionais - no que concerne à construção do conhecimento dos mesmos.

Para Santos et. al. (2008), o sistema hibrido se apresenta como possibilidade de dinamizar e flexibilizar o currículo dos cursos, com momentos presencias [físicos] e [virtuais], numa proposta integradora e inovadora. Esses autores também investigaram o uso pedagógico de um AVEA no decorrer de disciplinas semipresenciais, tendo como participantes doze professores de diferentes disciplinas e cursos e seus respectivos alunos. Nessa análise, verificaram como se desenvolveu o trabalho pedagógico do professor na semipresencialidade, com o uso de recursos midiáticos de um AVEA, identificando características, desafios, limites e avanços. Os resultados obtidos indicaram a aceitabilidade da semipresencialidade nos cursos de graduação, pelos acadêmicos, e o entusiasmo pela continuidade da proposta, pelos professores.

Timmor e Rymon (2010), em recente pesquisa, buscaram explorar aspectos do modelo de educação hibrida, suas potencialidades e suas barreiras. Ao investigarem estudantes em nível de graduação evidenciaram que, em um movimento gradual, o modelo de ensino híbrido propiciou maior grau de cooperação entre os estudantes e elevou seus desempenhos quando utilizavam, concomitantemente, ambos os modelos.

A seguir, descrevo a presente pesquisa e seus achados. 


\section{Métodos da pesquisa}

Quanto ao seu caráter geral, tratou-se de uma pesquisa qualitativa e, com base em seus objetivos, de um estudo de caso no qual, segundo Gil (1999), o pesquisador explora em profundidade um programa, um fato, uma atividade, um processo ou uma ou mais pessoas.

Os sujeitos da pesquisa eram estudantes de uma turma de um curso de especialização - vinculado a um programa de pós-graduação de uma instituição federal de ensino, do sul do Brasil. A pesquisa buscou obter impressões dos aprendentes sobre duas disciplinas da grade curricular do referido curso, em que um AVEA - o ambiente TelEduc - foi utilizado concomitantemente às aulas presenciais físicas. Com o intuito de preservar a privacidade dos sujeitos, optou-se por identificá-los por letras, em ordem alfabética. Dos vinte e cinco estudantes que iniciaram o curso, na época da oferta da primeira disciplina (D1), participaram dos fóruns, no ambiente TelEduc, vinte e um estudantes; na época da segunda disciplina (D2), foram dezesseis participantes.

Dos vinte e um estudantes que postaram comentários, ao menos uma vez, em pelo menos um dos fóruns, dezoito eram mulheres e três homens. A área de atuação profissional predominante era a docente, com algumas poucas exceções. No que diz respeito à formação acadêmica, havia forte predominância da área de Letras (doze tinham formação nessa área). Havia ainda três formados em Artes, dois em Filosofia, dois em Comunicação, um em Informática e um em Teologia. A idade dos sujeitos variava entre vinte e dois e quarenta e cinco anos.

Para capturar os detalhes das impressões dos participantes acerca da experiência híbrida da qual participaram, foram utilizados questionários (GIL, 1999) enviados e respondidos por e-mail - e a análise documental (GIL, 1999) dos registros das postagens dos educandos nos fóruns disponibilizados nas duas disciplinas. $O$ questionário foi enviado por e-mail aos educandos em três oportunidades (na tentativa de obter a colaboração dos sujeitos, não sendo re-enviados aos que já o haviam respondido). Dos dezesseis estudantes que ainda utilizavam o AVEA na época do envio do questionário, nove responderam. Quanto à análise documental, esta se baseou nas postagens dos estudantes em três fóruns de discussão (realizados durante a disciplina D1).

Os dados coletados foram submetidos a um processo de análise de conteúdo (MINAYO, 1993), cujos achados são apresentados a seguir.

\section{Análise de dados e seus achados}

A análise dos dados começou pelos depoimentos dos sujeitos ${ }^{2}$ acerca da relação educação-tecnologia, extraídos de três fóruns - todos em D1 - e de suas respostas à pergunta número três do questionário. Esta pergunta questionava os sujeitos quanto à 'utilização das Tecnologias da Informação e da Comunicação (TICs) em processos educativos'. Todos os sujeitos apontaram como positivas as possibilidades abertas pelas TIC em processos educativos, como mostram os excertos abaixo:

Percebe-se que o uso das TICs na educação possibilita mais interatvidade entre e professor e educando e permite mais autonomia por parte dos educandos na construção do saber (I).

$\mathrm{Eu}$, particularmente, acho fantástico por proporcionar uma troca de informações através da realidade tecnológica que vivemos. Mas em geral, nota-se um medo, senão uma resistência com essas ferramentas, o que bloqueia um pouco a adaptação destas principalmente pelos professores (B). 
Acredito que ainda é possível preparar uma boa aula sem usar recursos tecnológicos, mas também não tenho dúvidas de que com o auxílio da tecnologia o resultado pode ser ainda melhor $(\mathrm{E})$.

Todavia, os sujeitos $\mathrm{T}$ e A, além de se posicionarem favoráveis a essa relação, questionaram a forma como a tecnologia deve ser utilizada na educação para que tal relação não reproduza, via tecnologia, a mera transmissão de informações:

As TICS podem ser excelentes aliados nos processos educativos - "podem ser" - quando utilizadas de forma criativa e inteligente, no sentido de auxiliar no processo de aprendizagem/aperfeiçoamento do aprendiz. Elas não podem apenas ser utilizadas como ferramentas para continuar reproduzindo um formato tradicional e ultrapassado de ensino. As TICS estão à disposição para tornar o processo educativo mais conectado, mais coerente talvez, com a realidade virtual e tecnológica em que está inserida a maioria dos educandos $(\mathrm{T})$.

Deve ser bem explorada pelo professor antes de ser levada aos educandos, sendo de grande valia para os mesmos, no entanto sempre deve ser alertado para que se evite o uso indevido, lembrando que a finalidade das TICs é auxiliar na construção do conhecimento (A).

No fórum 'a integração da tecnologia nos processos de ensino e de aprendizagem', os estudantes se mostraram entusiasmados com a possibilidade da utilização pedagógica de ferramentas tecnológicas - mesmo aqueles que não atuam em sala de aula -, sendo esta a tônica da discussão deste tópico, como é possível perceber no recorte de alguns dos depoimentos:

Com certeza eu e todos estamos muito ansiosos por novidades para podermos utilizar dentro do nosso trabalho, e, também adaptar essas tecnologias dentro da realidade da escola em que trabalhamos, na prática (S).

Assim como as colegas espero contribuir para que a tecnologia de informação seja utilizada de forma produtiva na sala de aula e fora dela (K).

Apesar de não estar em sala de aula, como professora, tenho enorme interesse em conhecer novas tecnologias, pois penso que elas podem ser de grande ajuda em muitas atividades (Q).

Acredito que o educando se interessa mais pela aula quando há interatividade, e a informática proporciona esta interação entre: professor $\mathrm{X}$ educando $\mathrm{X}$ informação $(\mathrm{F})$.

Neste mesmo fórum, o depoimento de uma aluna se destaca pela profundidade de sua argumentação, mediante embasamento teórico nas ideias de Pierre Lévy (1999; 2004). Ao mesmo tempo, traz um exemplo concreto da utilização pedagógica da tecnologia em outro processo educacional; reforça a importância da busca do professor por esse conhecimento tecnológico, como outros colegas também relataram e; salienta a importância do aspecto motivacional na educação:

Bom, eu penso, como Lévy, que através dos signos e imagens nós atribuímos sentido à vida e ao mundo. Nesse sentido, acredito que as tecnologias podem ser um dispositivo de pensamento para que possamos alcançar essa significação, singularmente, em uma sala de aula por exemplo. Tive uma experiência pessoal com uso de tecnologias em um curso de 
extensão com educandos do ensino médio e técnico, e a partir disso posso constatar que o ensino é ainda muito carente no que diz respeito a este uso e quem mais se prejudica são os educandos, pois foi muito rica essa experiência e eles se envolveram muito, uma vez que aquele espaço era extra-curricular, e eles estavam ali apenas por seu desejo. E não faltavam nunca!! Assim, acredito que a inserção das tecnologias no ensino deve antes de mais nada ser uma busca de cada professor, pois ele é o primeiro que deve repensar suas práticas buscando significá-las de acordo com nosso tempo e realidade, em prol de uma melhor significação do processo de ensino-aprendizagem (R).

Ainda nesta temática, mas com outro foco, o fórum 'As novas tecnologias e as mudanças na percepção da realidade' revelou depoimentos bastante ricos, principalmente no que se refere à percepção docente da realidade dos educandos de hoje - os chamados nativos digitais. Essa percepção vai ao encontro do entendimento de Vygotsky (1982) sobre a relevância do meio histórico-cultural em que o sujeito está inserido para seu desenvolvimento cognitivo e também pode ser considerada como alicerce do pensamento pedagógico freireano, que considera essencial a busca do professor pelo conhecimento da realidade histórico-concreta de seus estudantes (FREIRE, 1997). Relatos e opiniões neste sentido são apresentados, logo abaixo:

[...] Com o estágio senti a necessidade de me aproximar da realidade que cerca o educando, concluindo que esta é a única forma de despertar interesse, de tornar a aula significativa e transpor a uma linguagem reconhecível por eles. Não me resta dúvida que a mídia é uma das principais influências na formação deste jovem, e que somente aliada a ela, poderei despertar o aprendiz para uma realidade que está fora dela. Desvendar a linguagem midiática, transformando o educando em sujeito interlocutor competente, dialogando com o mundo torna-se meu objetivo (C).

Concordo com você [C], sou da área da comunicação e mais do que nunca as tecnologias como a informática são a linguagem utilizada pelos jovens de hoje. Cabe sim a escola e aos professores se integrar a esses meios para conseguir despertar o interesse em sala de aula (I).

Realmente como disseram o uso das tecnologias em sala de aula é algo essencial, já que hoje os educandos não se interessam mais por aulas tradicionais onde o profess sor é o centro das atenções $(\mathrm{H})$.

Sabemos da dificuldade existente em fazer com que o educando preste atenção na aula. Cada vez mais percebemos educandos dispersivos. A tecnologia vem para ajudar o professor, possibilitando uma aula mais dinâmica (E).

Muito se discute, quando o tema é a utilização pedagógica da tecnologia, sobre a figura do professor - como já foi mencionado em alguns depoimentos trazidos até este momento. O terceiro fórum da disciplina D1 - 'O trabalho do professor e as novas tecnologias' - tinha esse enfoque em suas discussões. Somando-se aos pensamentos de Lévy (1999; 2004), Freire (1997) e Palloff e Pratt (2002), o consenso estabelecido naquele espaço foi o de que há a necessidade de o profissional docente estar preparado para utilizar essas ferramentas. Para tal, como defende Schlemmer (2004), é preciso manter-se atualizado, experimentar, mexer, "fuçar". Não basta ao professor adaptar-se às tecnologias, mas deve, ao mesmo tempo, ser protagonista dessa nova realidade; é necessário ensinar a como aprender com as TIC. As palavras dos sujeitos F, E e P corroboram a opinião destes autores: 
[...] Acredito que o professor deve manter-se em harmonia com a informática, porque cada vez mais a sociedade (educandos) interage com o tecnológico e por is so tornou-se obrigação do professor manter-se informado e atualizado em todos os níveis, principalmente tecnológicos, pois a informação e a educação estão intimamente interligadas $(F)$.

A resistência existente por parte de alguns professores às novas tecnologias realmente está relativa ao medo de usar, já que para alguns ainda prevalece aquela concepção de professor tem que saber tudo. Creio que reconhecer suas limitações é o primeiro passo, depois é preciso persistência, pois para nós, que não somos nativos digitais, a dificuldade é maior. Como diz a autora o caminho para o conhecimento está em usar, experimentar, sem medo de errar $(\mathrm{E})$.

Achei interessante também o fato de ela salientar que, para "se dar bem com a tecnologia" é preciso mexer, experimentar, ousar... pois aí é que residem as potencialidades $(\mathrm{P})$.

Observando os debates deste fórum, apresentados, a seguir, fica explícita a relação dialógica entre os aspectos trabalhados na aula presencial física e as interações no ambiente virtual, em um movimento pedagógico de versatilidade espaço-temporal, característica marcante em experiências hỉbridas de educação - com expressivo grau de interação e colaboratividade - igualmente apontada nas pesquisas de Timmor e Rymon (2010), Brod e Rodrigues (2009), Santos et. al. (2008) e Santana et. al. (2006).

O texto trouxe uma discussão que já havia sido feita na aula passada... a de que o trabalho com a tecnologia em sala de aula deve ser aproveitado... (D).

Através do artigo estudado na aula de ontem, pude concluir que o professor deve estar preparado para ser um orientador e não mais só um "fornecedor" de informações $(G)$.

Após uma breve leitura do texto e dos comentários feitos em aula, pude ver que ainda há receio ou resistência dos professores frente às tecnologias. A autora diz que "mexer" é o caminho para o conhecimento, para o descobrimento e para a aprendizagem e domínio seguro das tecnologias (K).

A análise dos dados, a seguir, tem com o pano de fundo a temática 'Utilizando um AVEA como suporte pedagógico ao ensino presencial tradicional'. Com base nesse tema, os sujeitos da pesquisa responderam quatro das cinco questões do questionário. Inicialmente, responderam 'Se sabiam o que é e, em caso positivo, qual a utilidade de um AVEA (Ambiente Virtual de Ensino e Aprendizagem)'. Dos nove sujeitos que responderam ao questionário, sete relataram já saberem o que é um AVEA enquanto que dois responderam desconhecer a expressão antes de cursarem o curso. Todos explicaram o que consideravam ser um AVEA e as respostas foram, em sua maioria, sucintas e diretas. Todavia, cabe destacar expressões-chave, características típicas de experiências educacionais híbridas "bem sucedidas", emergentes dessas respostas, como: troca, aprendizagem, atividades, construção, conhecimento, compartilhar, conteúdo, acompanhar, material e pesquisas. De uma forma geral - com algumas variações -, as respostas vão ao encontro das perspectivas de AVEA e de educação híbrida apontadas por Timmor e Rymon (2010), Brod e Rodrigues (2009), Schlemmer (2004) e D’Ávila (2003) e dos preceitos teóricos de Lévy (1999; 2003), Kenski (2003) e Palloff e Pratt (2002), sendo as mais detalhadas, as seguintes: 
Um AVEA é um espaço virtual com o qual se conta para auxílio no processo ensino-aprendizagem. Ou seja, um ambiente no qual se propõem atividades, debates, trocas, encontros entre grupos, visando o aperfeiçoamento, a integração e a construção do conhecimento (P).

Um Ambiente Virtual de Aprendizagem serve para que o educando possa compartilhar seu conhecimento com o professor e colegas, para que ele possa adquirir material didático através da WEB, para envio de trabalhos, execução de tarefas, agendamento de trabalhos e solução de dúvidas (K).

Trata-se de uma ferramenta de aprendizagem online, mais um recurso que o professor tem a disposição para melhorar/incrementar/atualizar suas propostas de trabalho para o educando $(\mathrm{T})$.

$\mathrm{Na}$ pergunta seguinte, os sujeitos foram questionados 'Se já haviam utilizado um AVEA em outra experiência educativa anterior' e, em caso afirmativo, foram solicitados a especificá-la. Quatro educandos responderam já terem participado de experiências educacionais mediadas por AVEA, anteriormente, enquanto que cinco afirmaram nunca terem vivenciado este tipo de experiência antes do curso de pósgraduação.

As perguntas quatro e cinco questionavam os sujeitos sobre as experiências que tiveram com educação hỉbrida - conciliando aulas tradicionais e atividades virtuais: 'Como avaliavam a utilização do Ambiente Virtual TelEduc como possibilidade de suporte/incremento às aulas presenciais físicas das duas disciplinas do curso de pósgraduação' e que citassem 'fatores positivos e negativos dessa experiência'. Os sujeitos acenaram como positiva a experiência que vivenciaram, como pode ser observado a seguir:

Avalio de forma bastante positiva, apesar de alguma resistência inicial, por desconhecimento ou antipatia mesmo. Acho que poderia ter sido ainda mais explorado, com mais participações e trocas entre os educandos, o que, entretanto depende do envolvimento e do interesse dos mesmos. Acredito que muitos se restringiram a fazer estritamente o que era solicitado nas tarefas do TelEduc, pela professora, quando poderíamos - todos - ter interagido mais. Ainda assim, acho que a experiência foi muito válida $(\mathrm{T})$.

Acredito que a utilização do TelEduc foi bastante interessante e produtiva [...] em minha opinião, foi extremamente válido. Além disso, o TelEduc é bastante interessante para que pudés semos ter portfólios virtuais com nossos trabalhos, podendo visitar as construções dos colegas, deixar comentários, debater e consultar material de apoio. Tanto que lembro que a utilização do TelEduc até foi sugerida para ser usada em outras disciplinas do curso de pós-graduação $(\mathrm{P})$.

Infelizmente o TelEduc só foi utilizado em duas disciplinas, que eram disciplinas voltadas à tecnologia de informação. Penso que as demais disciplinas poderiam ter utilizado tal ferramenta para promover fóruns de discussões, disponibilizarem materiais e etc. Nas disciplinas em que o Ava foi utilizado, avalio de forma positiva, pois além de termos o suporte através do TelEduc, as discussões promovidas foram de grande valia. Não lembro de nenhum fator negativo na experiência (E).

Possibilidade de fazer o próprio tempo para o estudo o que favorece educandos que trabalham e estudam; Possibilidade de interagir com todo o grupo e não somente trabalhar em grupos restritos; Facilidade de interação 
aos educandos mais tímidos com dificuldade de interação em aulas presenciais; Aquisição de conhecimentos básicos na área de informática aos educandos que em outras situações não teriam interesse pelo uso do computador (A).

O TelEduc possibilita a discussão de ideias e conceitos através de fóruns; trocas de diversas formas entre educandos e professores; feedback mais rápido tanto do professor quanto do educando. Não vejo nada de negativo nesta ferramenta, pois é algo que está aí para facilitar e não para complicar ou prejudicar o aprendizado (K).

Como é uma ferramenta de autonomia e interação ficou interessante e divertido o desenvolvimento de sua criação. Ainda mais por ser um ambiente que permite a continuação do projeto fora da sala de aula (I).

Para finalizar, $\mathrm{P}$ relatou detalhadamente situações concretas positivas e negativas do modelo híbrido experienciado nas duas disciplinas (D1 e D2):

Positivos: [...] Toda a nossa produção estava lá, publicada, para qualquer consulta necessária. Is so também facilitava que os colegas pudessem ler a produção uns dos outros, proporcionando trocas de experiências e ideias. [...] Os fóruns puderam auxiliar para que todos os educandos deixassem uma opinião sobre os temas debatidos anteriormente em aula ou propostos pela professora. [...] $\mathrm{O}$ ambiente abrigava os diferentes materiais de apoio disponibilizados pela professora. A qualquer dia e horário, podíamos acessar o TelEduc e resgatar o material, ou consultar no momento que melhor aprouvesse. Da mesma forma, os estudantes podiam sugerir materiais e links, que assim eram socializados com todos. Negativos: muitos colegas (me incluo também em alguns momentos) deixavam as participações para o último dia de prazo, sendo que alguns até passavam da data. Como era "virtual", acabávamos nos "baseando" em entregar as coisas mais perto (ou após) a data limite; em alguns momentos as pessoas "se perdiam" na utilização, e inclusive publicavam as avaliações em locais diferentes (uns no portfólio, outros no diário de bordo, etc.) (P).

Baseado na análise dos dados foi possível evidenciar que os estudantes pesquisados: consideram fundamental a utilização pedagógica das tecnologias; alertam sobre a forma como estas devem ser empregadas para que não se reproduza, via tecnologia, um ensino baseado na mera transmissão de informações; e avaliaram como bastante positiva a experiência pedagógica hỉbrida que vivenciaram lamentando, inclusive, que outras disciplinas do curso não a tenham oferecido.

\section{Considerações finais}

Os achados deste estudo reforçam a ideia de que o oferecimento de um espaço virtual de comunicação e interação entre docentes e estudantes, fora do espaço-tempo tradicional da sala de aula, pode contribuir efetivamente para aprendizagens, discussões colaborativas, práticas de pesquisa e manutenção de vínculos afetivos entre seus partícipes ${ }^{3}$. Outrossim, é importante que novos estudos relacionados à educação híbrida sejam realizados para que tenhamos cada mais elementos concretos sobre este tipo de atividade, seus benefícios, suas potencialidades e suas fragilidades.

A realização desta pesquisa buscou ainda colaborar com a discussão democrática acerca da relação educação-tecnologia e, embora o espaço disponível não permitisse que parte dos achados fosse revelada, sublinhou, a partir dos depoimentos dos sujeitos pesquisados, o aceno positivo à experiência educacional híbrida 
(semipresencial ou bi-modal), em um movimento dialógico entre os momentos presenciais físicos e as atividades presenciais virtuais. Essa abordagem avança em relação a projetos, programas e didáticas educacionais tradicionais que, muitas vezes, baseiam-se unicamente na disponibilização unidirecional de conteúdos "programáticos".

\section{Referências bibliográficas}

BROD, Fernando A.; RODRIGUES, Sheyla C. Ambiente virtual como espaço de aprendizagem colaborativa no ensino profissionalizante. In: Seminário de Pesquisa Qualitativa: Fazendo Metodologia, 8., 2009, Pelotas. Anais do... Pelotas, 2009.

D'ÁVILA, Cristina Maria. Pedagogia Cooperativa e Educação a Distância: Uma aliança possível. Educação \& Contemporaneidade, São Paulo, v.12, n.20, p.273-297, 2003.

FREIRE, Paulo. Pedagogia da Autonomia. 34.ed. Rio de Janeiro: Editora Paz e Terra, 1997.

GIL, Antonio C. Métodos e Técnicas de Pesquisa Social. 5.ed. São Paulo: Atlas, 1999. KENSKI, Vani M. Tecnologias e ensino presencial e a distância. 3.ed. Campinas, SP: Papirus, 2003.

LÉVY, Pierre. As tecnologias da inteligência - o futuro do pensamento na era da Informática. São Paulo: Editora 34, 1999. 203p.

LÉVY P. O ciberespaço como um passo metaevolutivo. Porto Alegre: Sulina, 2004. MINAYO, Maria Cecília de Souza. O desafio do conhecimento: pesquisa qualitativa em saúde. 2.ed. São Paulo - Rio de Janeiro: Hucitec-Abrasco, 1993.

PALLOFF, M., PRATT $K$. Construindo comunidades de aprendizagem no ciberespaço. Porto Alegre: Artmed, 2002.

ROCHA, H. V. Projeto TelEduc: Pesquisa e Desenvolvimento de Tecnologia para Educação à Distância. In: IX Congresso de Educação a Distância da ABED, 9., 2002, São Paulo. Anais do... São Paulo: ABED, 2002.

SANTANA, Otacílio; IMAÑA ENCINAS, José; COUTO JÚNIOR, Antônio F. Ensino presencial e virtual na disciplina de Metodologia de Pesquisa Florestal. In: Cobenge Ensino de Engenharia: empreender e preservar, 34., Passo Fundo. Anais do... Passo Fundo, 2006.

SANTOS, Cleusa R.; ZANETTI, Elisa N.; GIACOMAZZO Graziela F.; FIUZA, Patrícia J. O uso pedagógico do ambiente virtual de aprendizagem (AVEA) da UNESC: avaliação em disciplinas semipresenciais. In: XIV Congresso Internacional ABED de Educação a Distância, 14., 2008, Santos, Anais do... Santos: ABED, 2008.

SCHLEMMER, E. Comunidades Virtuais de Aprendizagem: possibilidades para repensar práticas didático-pedagógicas. In: V ANPEd Sul: Seminário de pesquisa em educação da região sul, 5., 2004, Curitiba. Anais do... Curitiba, 2004.

TIMMOR, Y.; RYMON, T. 'Don't imitate, innovate: the case of a hybrid education format in a management course'. Int. J. Information and Operations Manage ment Education, p. 6-22. 2010.

VYGOTSKY, L. S. Obras Escogidas II (Pensamiento Y Lenguaje). Moscú: Editorial Pedagógica, 1982.

\footnotetext{
${ }^{1}$ Utilizo a qualidade 'física' quando me refiro ao ensino presencial tradicional por acreditar que na virtualidade também há presença, só que de outra natureza. Nessa perspectiva, ao utilizar somente a expressão 'presencial', posso estar me referindo tanto ao 'presencial físico' quanto ao 'presencial virtual', o que por si só não diferencia as duas modalidades.

2 As frases dos depoimentos dos sujeitos da pesquisa foram submetidas a uma revisão ortográfica básica, vis ando facilitar/não comprometer o entendimento dos leitores das ideias expostas nos relatos,

3 Todavia, cabe salientar que AVEA mais robustos do que o ambiente TelEduc - principalmente em termos de possibilidades de interação, comunicação e colaboração - como o Moodle ou os Mundos 
Virtuais tipo Second Life -, tendem a propiciar resultados ainda mais satisfatórios em termos educacionais. Mas isso não pode servir de regra, pois são intencionalidade e os encaminhamentos pedagógicos que formam a base dos princípios que conduzem as experiências educacionais, independente de modalidade educacional e/ou dos recursos utilizados. 